\title{
CD161 to Lymphocyte Ratio Measurement
}

National Cancer Institute

\section{Source}

National Cancer Institute. CD161 to Lymphocyte Ratio Measurement. NCI Thesaurus.

Code C122105.

The determination of the ratio of CD161 expressing cells to total lymphocytes present in a sample. The measurement by be expressed as a ratio or percentage. 